\title{
Correction to: Towards Porting Astrophysics Visual Analytics Services in the European Open Science Cloud
}

\author{
Eva Sciacca, Fabio Vitello, Ugo Becciani, Cristobal Bordiu, \\ Filomena Bufano, Antonio Calanducci, Alessandro Costa, \\ Mario Raciti, and Simone Riggi
}

\section{Correction to: \\ Chapter "Towards Porting Astrophysics Visual Analytics Services in the European Open Science Cloud" in: \\ K. Arai et al. (Eds.): Intelligent Computing, AISC 1230, https://doi.org/10.1007/978-3-030-52243-8_43}

In the original version of the book, the following belated correction has been incorporated: The affiliation of Mario Raciti has been changed from "INAF, Catania Astrophysical Observatory, Catania, Italy" to "Università di Catania, Dipartimento di Matematica e Informatica, Catania, Italy". 